\title{
Reverse Scarf Osteotomy for Hallux Varus following Surgery for Hallux Valgus
}

${ }^{1}$ Rakesh B Dalal, ${ }^{2}$ Ricci Gary Edward Plastow, ${ }^{3}$ Rajesh Rachha

\begin{abstract}
Hallux varus is a much rarer deformity in clinical practice than hallux valgus. It can be congenital, associated with inflammatory arthropathy or iatrogenic due to overcorrection in hallux valgus surgery. There have been many treatments suggested but no gold standard has been found. We will describe a simple surgical procedure involving the scarf osteotomy to reverse the overcorrection of hallux valgus.
\end{abstract}

Keywords: Hallux, Varus, Scarf, Osteotomy.

How to cite this article: Dalal RB, Plastow RGE, Rachha R. Reverse Scarf Osteotomy for Hallux Varus following Surgery for Hallux Valgus. J Foot Ankle Surg (Asia-Pacific) 2014;1(2):52-54.

Source of support: Nil

Conflict of interest: None

\section{INTRODUCTION}

Hallux varus is a rare complication of surgery for hallux valgus. The incidence ranges from 2 to $15 \% .{ }^{1-4}$ Milder degrees of hallux varus can be treated symptomatically but more severe degrees may need surgery. There are many surgical options described to treat this problem, including osteotomies, tendon transfer and 1st MTP joint arthrodesis. The most common operation known is the extensor tendon transfer. ${ }^{5,6}$ It has shown low recurrence rates of $4.4 \%$ in a meta-analysis of 68 procedures, ${ }^{7}$ but it is known to reduce hallux extension power and is technically difficult.

In the past metatarsophalangeal (MTP) joint, fusion was the standard treatment for patients, 8,9 despite no significant arthritis. Therefore, surgeons have tried to devise joint preserving osteotomies to correct the deformity. The distal chevron osteotomy has been described ${ }^{4}$ in 19 patients with a recurrence rate of $10 \%$. The reverse

\footnotetext{
${ }^{1}$ Consultant, ${ }^{2}$ Registrar, ${ }^{3}$ Senior Clinical Fellow

${ }^{1}$ Department of Trauma and Orthopedics, Stockport NHS Foundation Trust, University of Manchester, United Kingdom

${ }^{2}$ Department of Trauma and Orthopedics, Stockport NHS Foundation Trust, United Kingdom

${ }^{3}$ Department of Trauma and Orthopedics, Stockport NHS Foundation Trust, Stepping Hill Hospital, United Kingdom

Corresponding Author: Rakesh B Dalal, Consultant, Department of Trauma and Orthopedics, Stockport NHS Foundation Trust, University of Manchester, United Kingdom, e-mail: rdalal7119@aol.com
}

austin osteotomy was described in $1987^{10}$ but no single approach has large enough numbers to prove it is the gold standard.

The reverse scarf osteotomy is a new approach that has been described in the literature ${ }^{11}$ with only a few patients. We will describe the exact technique to preserve the MTP joint in patients following hallux valgus surgery.

\section{INDICATIONS AND CONTRAINDICATIONS}

Currently, our indication for surgery is patients that have an iatrogenic cause of hallux varus. It is usually due to over correction of hallux valgus surgery. We do feel the indications may be extended to the other causes of hallux varus in the future.

\section{PREOPERATIVE PLANNING}

The patient is seen in a preoperative clinic with the consultant and recent $\mathrm{X}$-rays of the foot are checked or ordered that day. Anteroposterior (AP) and lateral weightbearing views are obtained. The hallux varus angle is measured with lines drawn down the metatarsal midline shaft and the midline of the phalangeal shaft. The patient has surgery as an outpatient.

\section{TECHNIQUE}

General or regional anesthesia is used. We always use a long acting block for regional anesthesia. The patient is supine, with a sandbag underneath the ipsilateral buttock. The surgery involves two main components:

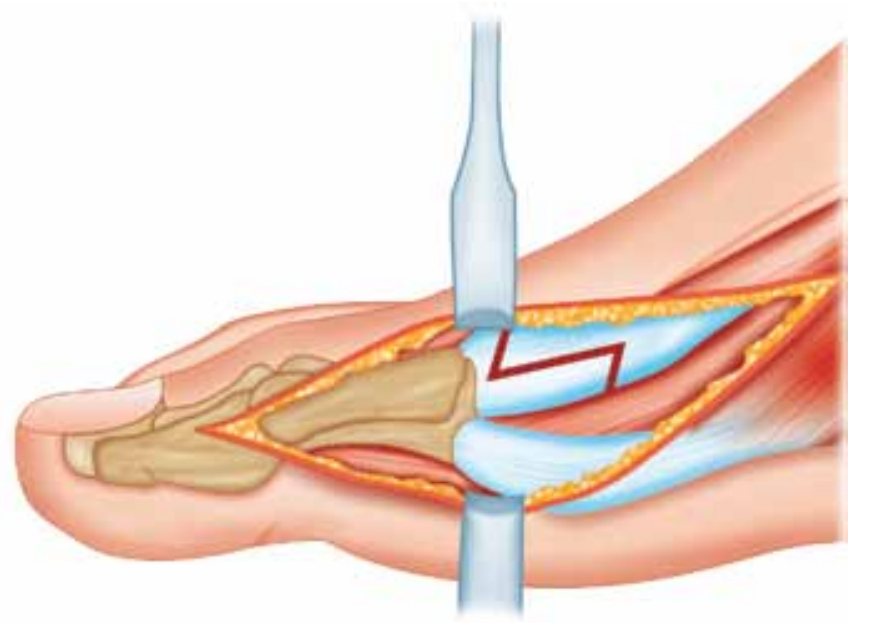

Fig. 1: Medial incision step cut 
lateral reefing and the medial release with osteotomy. The medial incision is made first to release the medial capsule and remove any pre-existing metal work. One $3 \mathrm{~cm}$ step cut incision is made in the medial capsule which facilitates lengthening (Fig. 1).

In iatrogenic hallux varus, there is usually no significant medial tightening, but instead lateral laxity that seems to be the common imbalance.

The 1 st web space incision is then made, $4 \mathrm{~cm}$ long to excise scar tissue and reef the adductor hallucis tendon. Where possible the adductor remnants are reattached to the base of the lateral proximal phalanx by means of an intraosseous suture. Where there has been over release of the flexor hallucis brevis tendon, this can be corrected by reefing this structure.

Final tightening laterally is only done after osteotomy fixation. Attention is then turned to the medial osteotomy. The senior author uses the shorter version of the scarf osteotomy. One stress limiting drill hole is placed within the center of the metatarsal head with a $1.6 \mathrm{~mm}$ K-wire.

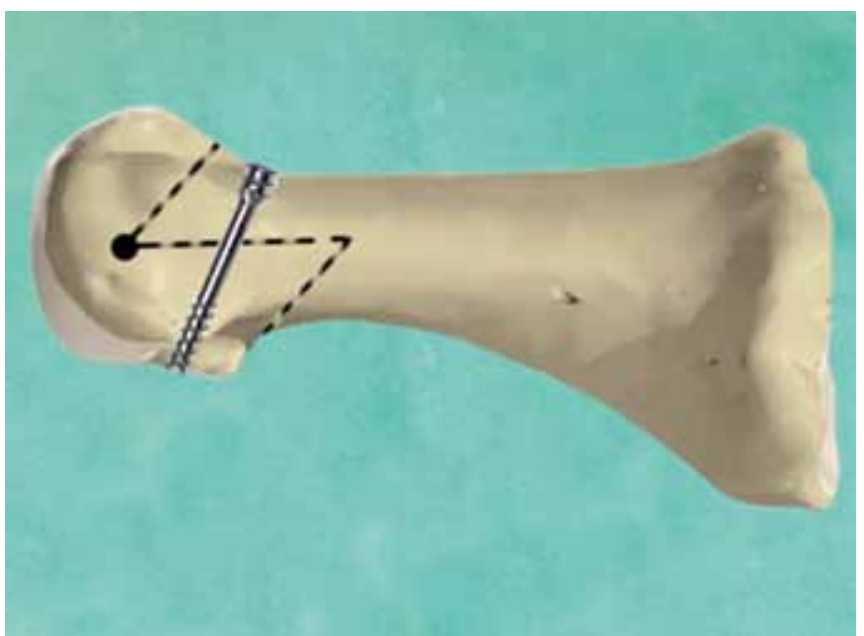

Fig. 2: Reverse short scarf osteotomy cuts shown with screw position on the lateral view

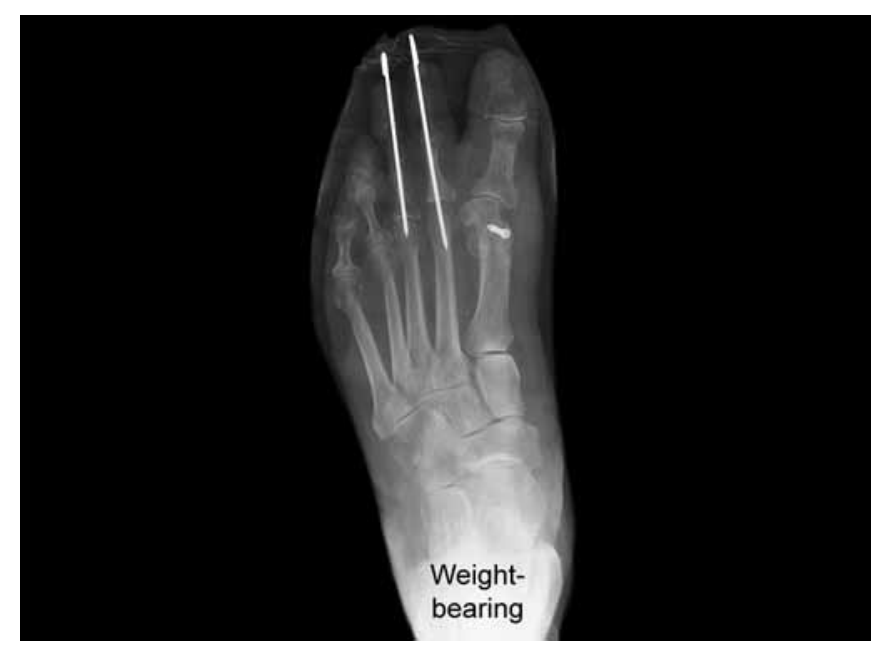

Fig. 4: Preoperative $X$-ray showing hallux varus
The horizontal limb of the osteotomy is made in the usual fashion. The length of the limb is $2 \mathrm{~cm}$ in the short scarf osteotomy. The distal vertical/oblique limb is made and then the proximal vertical/oblique limb is made.

The distal fragment is moved medially, in the direction opposite to the standard scarf osteotomy. After the required displacement is achieved, it is transfixed temporarily with a K-wire. Although no guidelines exist for the amount of displacement necessary, relocation of the sesamoids under the metatarsal appears to be a good indicator. The correction is checked under the image intensifier and the osteotomy is fixed with a single BOLD cannulated compression screw. Figure 2 shows the osteotomy cut and fixation with screw from a lateral view.

Figure 3 shows the AP view of the osteotomy and displacement occurring. The far right image shows fixation with the compression screw.

The lateral reefing is now completed and the capsule is closed with a 2 vicryl suture. The wounds are closed in a standard fashion after the capsule repair.

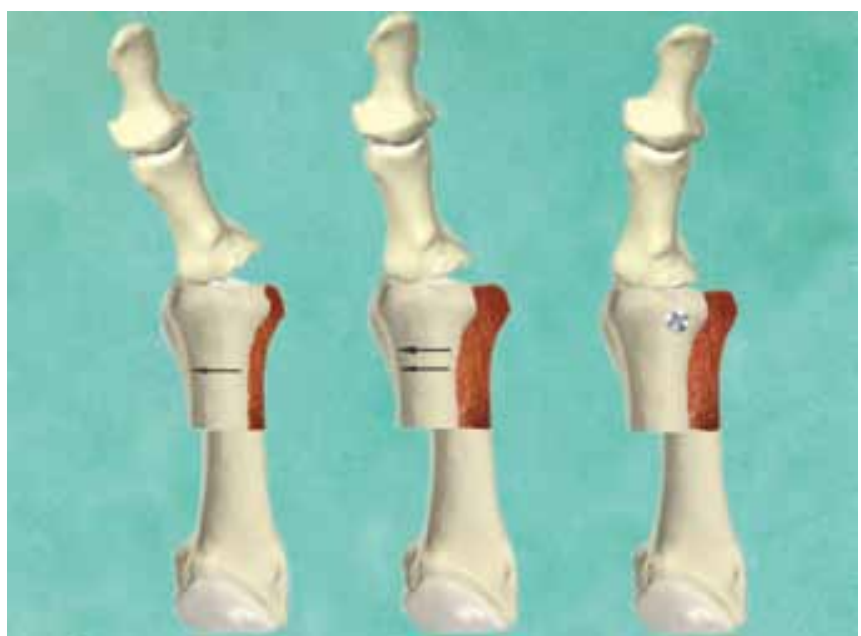

Fig. 3: The translation of MTP joint following osteotomy cuts. Screw position shown in final image on AP views

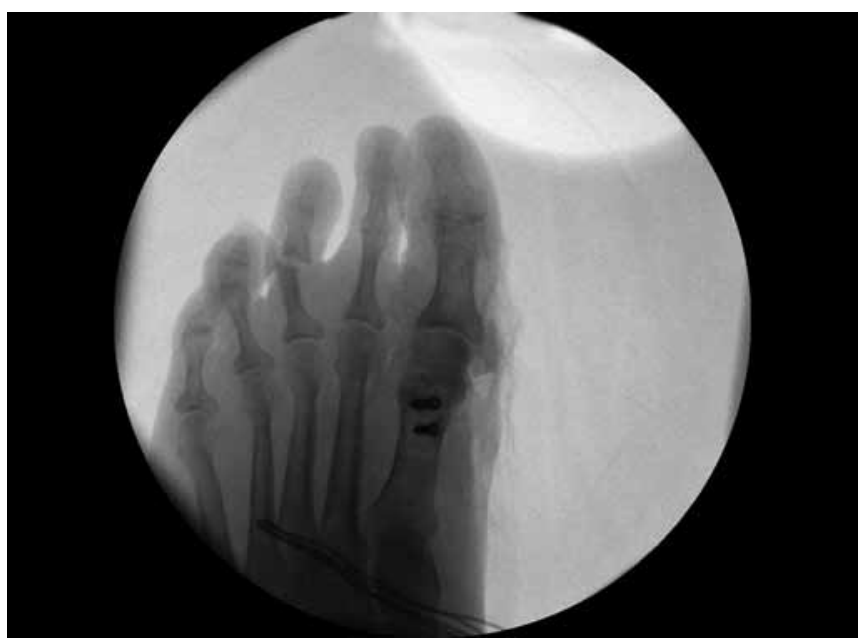

Fig. 5: Intraoperative X-ray showing correction of hallux varus 
X-rays showing the preoperative hallux varus from previous surgery and intraoperative correction (Figs 4 and 5).

\section{POSTOPERATIVE MANAGEMENT}

The patient is placed into a rockerbottom postoperative shoe to allow full weightbearing for 6 weeks. The patient is reviewed at 3 weeks to review the wound. The patient is initially seen by the physiotherapist on the same day as the operation to learn how to use crutches. At 6 weeks, if the repeat $\mathrm{X}$-ray looks fine then the shoe is removed and full weight-bearing is commenced, and the patient is discharged to physiotherapy.

\section{RESULTS}

We have only a small series of five patients currently. The follow-up is from 6 weeks to 1 year. There are no complications and no recurrence of hallux varus so far.

\section{COMPLICATIONS}

- Infection

- Metal work failure

- Neurovascular injury

\section{POSSIBLE CONCERNS, FUTURE OF THE TECHNIQUE}

We believe this is a simple, effective technique for all iatrogenic hallux varus patients needing surgical intervention. We hope the technique can be used for all causes of hallux varus in the future.

\section{REFERENCES}

1. Devos Bevernage B, Leemrijse T. Hallux varus: classification and treatment. Foot Ankle Clin 2009;14:51-65.

2. Edelman RD. Iatrogenically induced hallux varus. Clin Pediatr Med Surg 1991;8:367-382.

3. Hawkins FB. Acquired hallux varus: cause, prevention and correction. Clin Orthop 1971;76:169-176.

4. Choi K, Lee H, Yoon Y, et al. Distal metatarsal osteotomy for hallux varus following surgery for hallux valgus. J Bone Joint Surg 2011;93:1079-1083.

5. Goldman F, et al. EHL tendon transfer for correction of hallux varus. J Foot Ankle Surg 1993;32(2):126-131.

6. Lau JT, Myerson MS. Modified split EHL tendon transfer for correction of hallux varus. Foot Ankle Int 2002;23(12): 1138-1140.

7. Plovanich E, et al. Failure after soft tissue release after tendon transfer following flexible iatrogenic hallux varus: a systematic review. J Foot Ankle Surg 2012 March;51(2):195-197.

8. Groulier P, et al. Postoperative iatrogenic hallux varus. Surgical treatment. Apropos of 19 cases. Revue de chirurgie orthopaedique et reparatice de l'appareil moteur 1992;30(3): 264-266.

9. Mills JA, et al. Hallux varus. J Bone Joint Surg 1989;71B(3): 437-440.

10. Bilotti MA, et al. Reverse austin osteotomy for correction of hallux varus. J Foot Surg 1987;26(1):51-55.

11. Kannegieter E, Kilmartin TE. The combined reverse scarf osteotomy and opening wedge osteotomy of the proximal phalanx for the treatment of iatrogenic hallux varus. The Foot 2011;21:88-91. 